\title{
Amabel Míguez de la Sierra (2017) ilustra las Jácaras de Quevedo (1645)
}

\section{Amabel Míguez de la Sierra (2011) ilustrates Quevedo's Jácaras}

\section{Emmanuel Marigno}

Université de Saint-Etienne

FRANCIA

emmanuel.marigno@univ-st-etienne.fr

[Hipogrifo, (issn: 2328-1308), 6.1, 2018, pp. 347-363]

Recibido: 06-03-2017 / Aceptado: 07-04-2017

DOI: http://dx.doi.org/10.13035/H.2018.06.01.26

Resumen. Este artículo analiza las ilustraciones de la artista Amabel Míguez de la Sierra a las Jácaras de Quevedo, evidenciando los vínculos de las imágenes retóricas del escritor barroco con las iconográficas de la artista postmoderna. El propósito es resaltar la manera como estas ilustraciones se enmarcan en un contexto bibliófilo general, a la vez que se distinguen mediante una narración plástica original, que moderniza la germanía quevedesca adaptándola a los cánones postmodernos.

Palabras clave. Quevedo; recepción; ilustración.

Abstract. This article analyzes the illustrations of the artist Amabel Míguez de la Sierra to the Jácaras of Quevedo, demonstrating the links of the rhetorical images of the baroque writer with the iconographic ones of the postmodern artist. The intention takes root in demonstrating the way these illustrations take place in a context general bibliophile, simultaneously that differ by means of a plastic original language, which modernizes the Quevedo's germanía adapting it to the postmodern codes.

Keywords. Quevedo; Reception; Illustration.

\section{INTRODUCCIÓN}

Las ilustraciones de Amabel Míguez de la Sierra, grabadora y pintora gallega contemporánea, se arraigan filológicamente en los criterios que definen las jácaras en general y las de Francisco de Quevedo en particular: personajes -izas y 
jaques-, temática hampesca -matanzas, prostitución y demás robos-y lengua de germanía, todo ello entroncado con la lógica conceptista.

Estas representaciones de marginales y rebeldes se enmarcan en los criterios editoriales de la creación bibliófila, con unas doce a quince ilustraciones junto al texto. Como suele acontecer en el caso de ilustraciones dedicadas a géneros cortos (poemas, novelas cortas, etc.), cada jácara dispone aquí de ilustración propia, a diferencia de los géneros largos como la novela, en que las imágenes son mucho menos numerosas, lo cual supone que cada representación iconográfica ilustra un fragmento del texto únicamente o que funciona como ilustración a un ambiente más general y global.

Estas obras, fruto de una técnica mixta entre grabado y pintura, llevan títulos que son citas directamente sacadas de las propias jácaras, lo mismo que hace Antonio Saura en las ilustraciones a los Sueños (1971) de Quevedo (Fig. 0) a partir de la traducción francesa del Sieur de la Genestẹ, lo cual establece un sistema intra-discursivo ${ }^{2}$ entre el hipertexto icónico y su hipotexto escritural ${ }^{3}$.

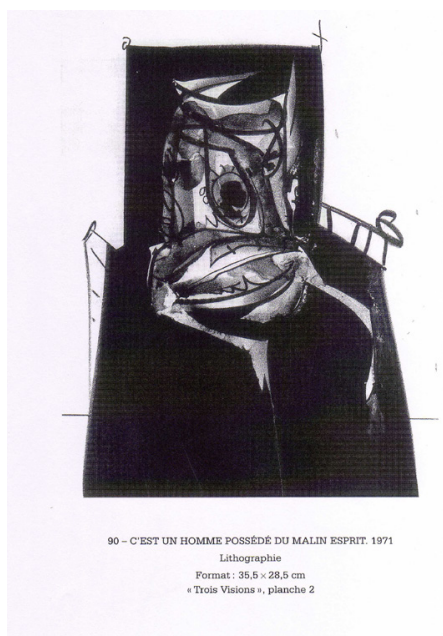

Figura 0

Antonio Saura, «Le sergent de ville démoniaque », 1971, litografía. Copyright Sucession Antonio Saura, <www.antoniosaura.org>, Vegap 2010.

Dichas relaciones icono-textuales van íntimamente vinculadas en estas obras híbridas, donde incluso se pinta directamente el texto dentro de la propia imagen, como en las ilustraciones a la jácaras $2^{4}$, «Respuesta de La Méndez a Escarramán», o la 13, «Postrimerías de un rufián» (Fig. 1), técnica claramente relacionada -entre otros- con otro hipertexto icónico mexicano que es el de José Luis Cue-

1. Saura, 1971.

2. Kerbrat-Orecchioni, 1980.

3. Maingueneau, 1996.

4. Sigo el orden de Marigno, 2000 
vas, quien en sus ilustraciones a Homage to Quevedo $(1969)^{5}$ también hace uso de este recurso icono-textual (Fig. 2).

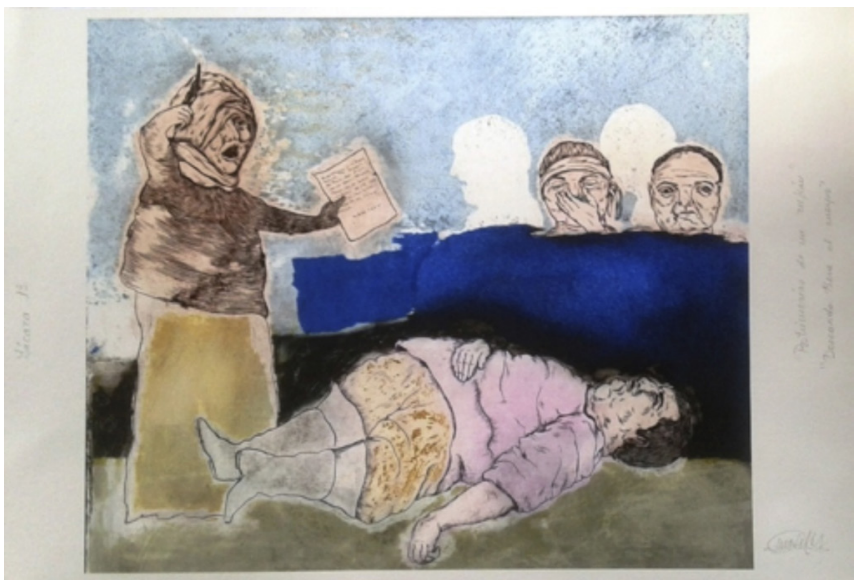

Figura 1

Amabel Míguez de la Sierra, Postrimerías de un rufián, 2011, técnica mixta.

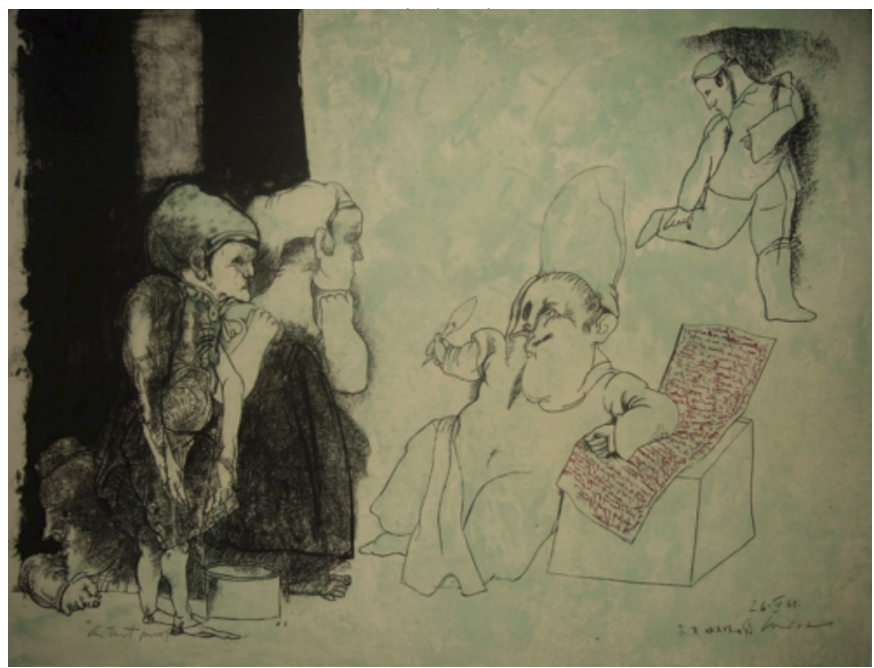

Figura 2

José Luis Cuevas, Lo feo de este mundo I, 1969, aguafuerte. Litografía, A/P, $56.5 \times 76.5 \mathrm{~cm}$

(C) Museo José Luis Cuevas

Originalidad pues de todo un sistema icono-textual, el de Amabel Míguez de la Sierra, en un tiempo singular y relacionado con toda una generación de ilustradores bibliófilos contemporáneos que, a su vez, se arraigan en toda una tradición pictó- 
rica que encontramos ya en la cultura visual del Siglo de Oro, como lo ilustra por ejemplo La conversión de San Pablo (1675-1682)6 de Bartolomé Esteban Murillo.

Se tratará aquí de vincular las ilustraciones de la artista con la écfrasis, la descriptio, la germanía y la prosografía ${ }^{7}$ de Quevedo; intentaré también hacer hincapié en la modernidad de estas técnicas artísticas de representación, que ponen estas figuras de rebeldes pertenecientes a la centuria del XVII al alcance del receptor postmoderno. El aparato crítico será el evidente armazón de semiótica textual e iconográfica que enlaza la imagen escritural con la pictórica, a la que añado los conocidos conceptos de la filosofía post-moderna.

\section{LOS PERSONAJES EN SU CONTEXTO ESPACIO-TEMPORAL}

Izas y jaques vienen plasmadas en la obra de Amabel Míguez de la Sierra, casi siempre, fuera de todo contexto espacio-temporal; los personajes no se ubican en una época ni lugar determinados, como si no se tratase de pintar una temporalidad precisa sino de representar un prototipo ahistórico del marginal, y de hecho todavía vigente hoy día de alguna forma. Precisemos que un diminuto número de elementos del decorado que rodea a estos héroes hampescos, como el banasto o las galeras, son por cierto castigos propios de las peores fechorías de los jaques del $\mathrm{XVII}$, sin por lo tanto llegar a constituir un paradigma determinante y significativo en el conjunto del sistema gráfico de nuestras ilustraciones por motivos cuantitativos - débil número de referentes espacio-temporales-y de recurrencias -muy pocas repeticiones de estos mismos referentes.

Pero existe otro espacio en estas ilustraciones, un territorio plástico y mental encarnado por los propios personajes que resultan ser a la vez contenido, contexto y lenguaje. Por ejemplo, la forma del cuerpo del jaque (Fig. 3) se desdibuja en una nueva forma espacial que parte de su cuerpo, lo deconstruye y traslada desde la categoría de lo humano hacia lo material; vuelto ancla marítima, los jaques son deshumanizados, como si se diluyera en el mar lo que les queda de humanidad.

6. Óleo sobre lienzo, 125 × $169 \mathrm{~cm}$. La relación Texto / Imagen radica en el «Saule, Saule, quid me persequeris» que sale de la boca de Dios en dirección de Pablo, cita sacada de Hechos de los Apóstoles, cap. 9. Lo interesante es que el hipotexto gráfico de Murillo había sido el desaparecido lienzo de Rubens de 1620, que conoció Murillo gracias a un grabado creado a partir del original de Rubens.

7. Pozuelo Yvancos, 1980. 


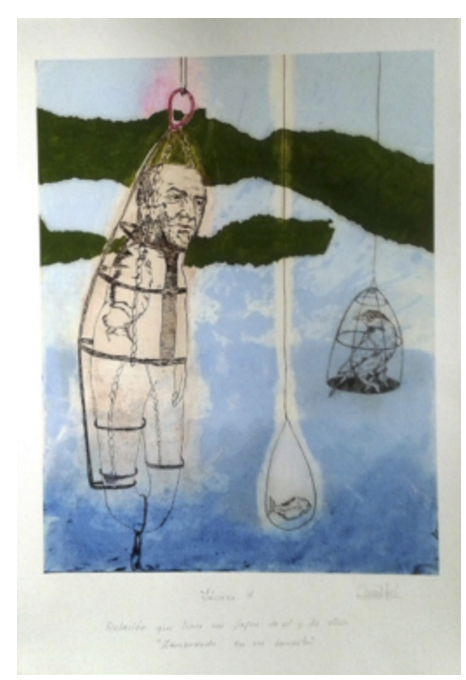

Figura 3

Amabel Míguez de la Sierra, Relación que hace un jaque de sí y de otros, 2011, técnica mixta.

(c) A. M. de la Sierra

Este hacer/deshacer de rizomas estéticos implica un discurso ético. Los malos tratos que le inflige la justicia al cuerpo del jaque deshumanizan aún más a estos maleantes, estableciéndose así un diálogo entre el cuerpo institucional y el cuerpo del maleante: ambos resultan inhumanos, el uno por ser incapaz de respetar el cuerpo institucional y el otro por ser ineficaz en insertar al marginal en el cuerpo colectivo ${ }^{8}$.

Esta inhumanidad rufianesca se lee también en la soledad y casi aislamiento ${ }^{9}$ del jaque, que contrasta con las izas siempre en compañía ora de «un menino del padre» - jácara 2-, ora de un nuevo jaque - jácara 3-, ora de amigas de infortunio -jácara 10-(Figs. 4, 5 y 6). El jaque desempeña así una función de ruptura -respecto al orden político y socio-cultural- y destrucción -matanzas, prostitución, robos, etc.-, cuando la iza cumple con el papel de revelar: en efecto, ella es quien sufre la brutalidad del jaque igual que la indiferencia de la justicia y sociedad -que no solo la ignoran sino que además la castigan, siendo así las izas dos veces víctimas. 

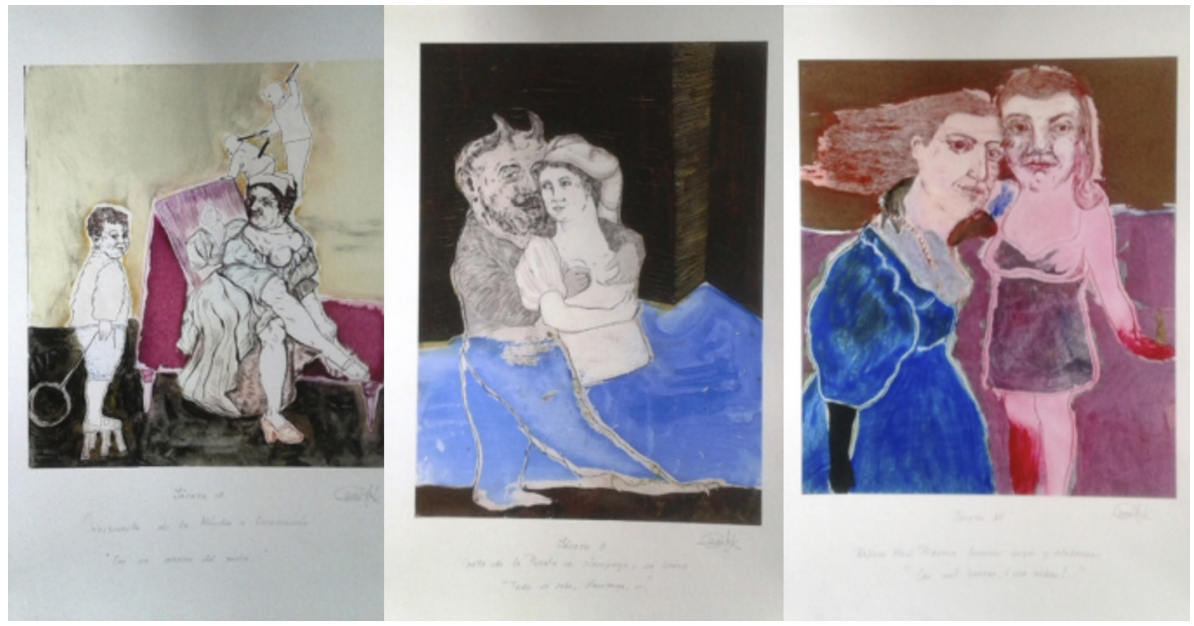

Figuras 4, 5, 6

Amabel Míguez de la Sierra, Respuesta de la Méndez a Escarramán, Carta de la Perala a Lampuga su bravo y Refiere Mari Pozorra honores suyos y alabanzas, 2011, técnica mixta.

(C) A. M. de la Sierra

La función del espacio y de los personajes que lo habitan parece ser pues la de representar una imagen prototipo del marginal deshumanizado y deshumanizador, más allá del tiempo y del espacio, gracias a recursos plásticos modernizados y sin embargo conformes a la escritura de Quevedo.

\section{PINTAR EL ESTILO DE QUEVEDO}

Las ilustraciones de Amabel Míguez de la Sierra reescriben en el ámbito gráfico el funcionamiento de la escritura visual de Quevedo ${ }^{10}$. La hibridez de la descriptio física de Quevedo recorre en efecto estas ilustraciones a las jácaras. La ilustración a la jácara 3 por ejemplo escenifica el cuerpo de la Perala, iza de Lampuga, junto con su nuevo jaque «[...] un mulato / corchete fondos en zurdo, / barba y bigotes de ganchos» (vv. 24-26). La imagen gráfica se arraiga aquí en la imagen retórica, pero viene completada por la imaginación de la artista. Por ejemplo, encontramos en el rostro de la ilustración «el bigote de ganchos» y la tez mulata que contrasta con lo blanco de la piel de la Perala (Fig. 7), mientras la referencia al origen infernal del mulato evocado por el adjetivo «zurdo» en el texto, la tenemos en los cuernos diabólicos del mulato. Sin embargo, Quevedo deja en vacío todo el resto del cuerpo del mulato que la artista completa con unas piernas rematadas con garras demoníacas en lugar de pies, prolongando así la lógica interna del texto de Quevedo.

Llama la atención la sinécdoque gráfica aplicada a la Perala, como si le faltase una cola que hubiera podido ser la de una sirena, sugerida por la superficie azul

10. Levisi, 1968 y Moreale, 1956. 
en la parte inferior de la ilustración, espacio igualmente presente en la respuesta de Lampuga rodeado de sardinas en la jácara 4 (fig. 8). La suma de ambas ilustraciones - que vienen funcionando de hecho como un díptico gráfico-y de la forma epistolar que ilustran se asemejan a un concepto gráfico que le sugiere al receptor posibles continuaciones al cuerpo de la iza, gracias a conceptos visuales por analogía: por cierto, a los pies demoníacos del jaque sucede en la mente del receptor una cola de sirena -Figs. 7 y 8 a las jácaras 3 y 4.

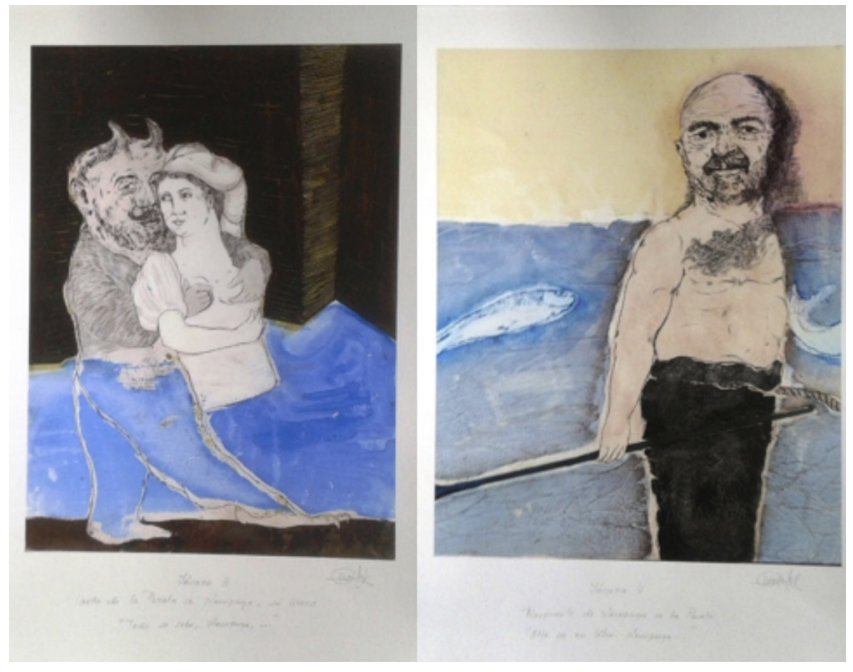

Figuras 7 y 8

Amabel Míguez de la Sierra, Carta de la Perala a Lampuga su bravo y Respuesta de Lampuga a la Perala, 2011, técnica mixta.

(c) A. M. de la Sierra

Esta hibridez la volvemos a encontramos - aunque con otras categorías visuales - en la ilustración a la jácara 5 «Villagrán refiere sucesos suyos y de Cardoncha». La ilustración (Fig. 9) hace hincapié en la veneración que le manifiesta Villagrán a su iza, Antoñuela Jerigonza, «más linda que mil ducados / y más bella que cien flotas» (vv. 43-44). El jaque, representado de medio cuerpo y escorzado, admira desde un tamaño muy inferior a la iza a la que está enalteciendo y de la que Amabel Míguez de la Sierra representa solo una cabeza en forma de sinécdoque. Llama la atención la expresión de este rostro que, a pesar de ubicarse en un zócalo, resulta muy expresivo, vivo y casi de carne y hueso. Consigue aquí la artista una hibridez gráfica que une lo mineral y lo humano, como para expresar en el hipertexto icónico la hipérbole del hipotexto escritural. 


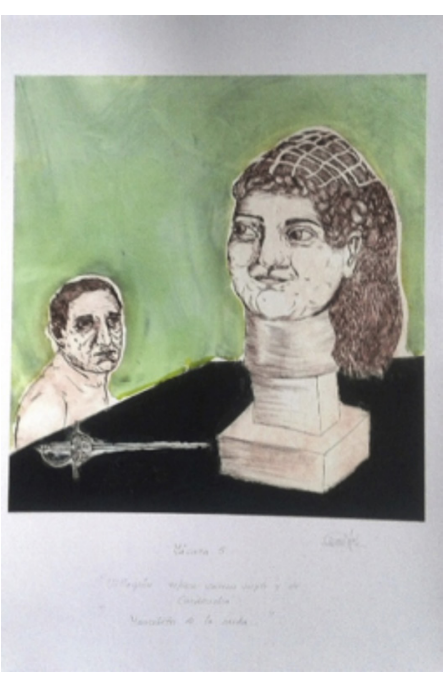

Figura 9

Amabel Míguez de la Sierra, Villagrán refiere sucesos suyos y de Cardoncha, 2011, técnica mixta.

(c) A. M. de la Sierra

Otra ilustración de la «hibridez» quevedesca es la ilustración a la jácara 7 «Relación que hace un jaque de si y de otros», en que Amabel Míguez de la Sierra traduce gráficamente el verso «Zampuzando en un banasto», donde Quevedo describe un mundo de prisiones desde la focalización interna del jaque. Aquí, la artista fusiona las líneas que delimitan el cuerpo del jaque con las que delinean el banasto en que se encerraba al rufián antes de zampuzarlo en el mar. El hipálage de la línea gráfica genera una cosificación del jaque, a lo que se añade el lenguaje cromático; en efecto, la paleta de azules mezcla el «cuerpo-banasto» del jaque con el agua del mar, como si se estuviese diluyendo, desapareciendo, tanto más cuanto que el jaque parece ser inconsistente, resulta como transparente, pues no viene representado sino mediante líneas, como una forma hueca y sin contenido. Esta paleta de azules fusiona el mundo acuático en que están el jaque y el pez, con el celeste donde está el pájaro enjaulado: pájaro y jaque se miran, como confundiéndose en un mismo encerramiento. La ilustración, uniendo formas humanas, acuáticas y celestes en un mismo lenguaje de líneas gráficas y en una compartida paleta de azules fríos, consigue unificar en un mismo "pliegue» ${ }^{11}$ todas las categorías faltas de libertad citadas por la voz poética en esta jácara (Fig. 3).

En estos cuerpos deconstruidos e híbridos, llama la atención el paradigma grafico de la mano. Como herramienta del escritor y del grabador, la mano cobra una función constructiva, en particular, en las señaladas ilustraciones donde el texto está dentro de la imagen -jácaras 2 y 13 por ejemplo- (Fig. 1). Por lo contrario, faltarán manos cuando la navaja presencia la ilustración, como en la jácara 6 (Fig. 10).

11. Deleuze, 1988. 


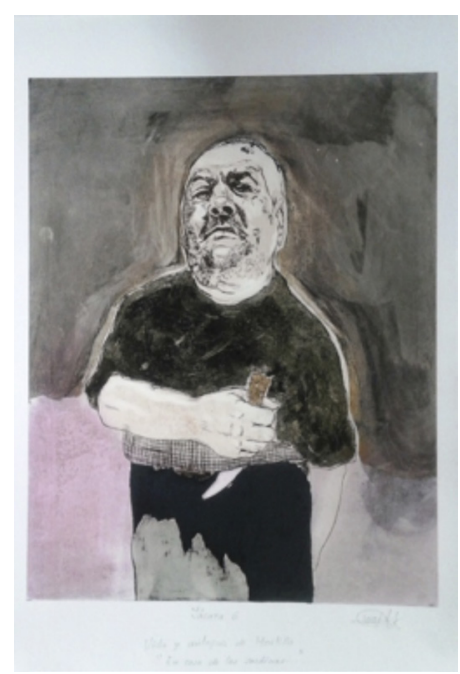

Figura 10

Amabel Míguez de la Sierra, Vida y milagros de Montilla, 2011, técnica mixta.

(c) A. M. de la Sierra

Esta dialéctica gráfica entorno a la mano se arraiga en parte en el hipotexto gráfico cuevista precedentemente señalado, en que José Luis Cuevas acaba resumiendo a Quevedo bajo la figura «sinecdótica» de la mano (Fig. 11); mano que consta como una señal generacional, puesto que el ilustrador franco-español François Maréchal'2, ilustrador del quevedesco romance Testamento de don Quijote (1987), reúne a Cervantes, a Quevedo y a sí mismo respectivamente como escritores y artista, en el símbolo de una mano con pluma de avestruz (Fig. 12). 


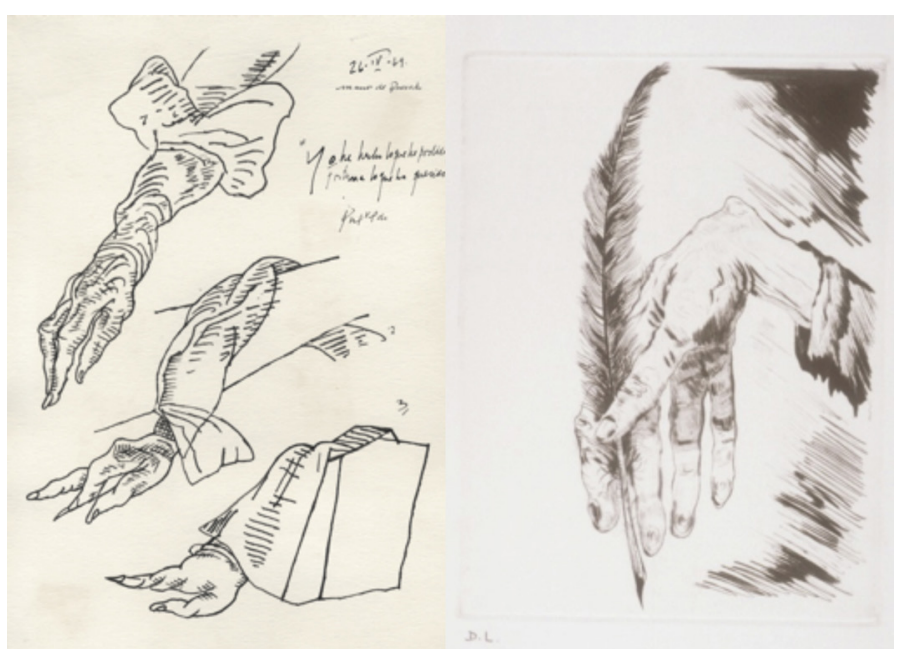

Figuras 11 y 12

José Luis Cuevas, Manos de Quevedo, 1969, dibujo a pluma sobre papel (C) Museo José Luis Cuevas

François Maréchal, Testamento de don Quijote, 1987, aguafuerte

(c) Casariego

La lengua de germanía también está presente en la técnica gráfica de Amabel Míguez de la Sierra. La ilustración a la jácara 1, «Ya está metido en la trena / tu querido Escarramán», ilustra gráficamente el vocablo de germanía trena (Fig. 13). En efecto, la artista le muestra al espectador-lector a un Escarramán en segundo plano, igual que en el verso después del sustantivo trena; trena, en primer plano de la ilustración, retoma la sintaxis poética del texto a la vez que la enigmática lengua de germanía que solo se entiende entre jaques. Lo mismo que el lector de las jácaras se pregunta qué es trena, el espectador-lector de las ilustraciones debe interpretar esas líneas negras, dispuestas de forma irregular y que separan a Escarramán desde su espacio ficticio del espectador-lector en la realidad. 


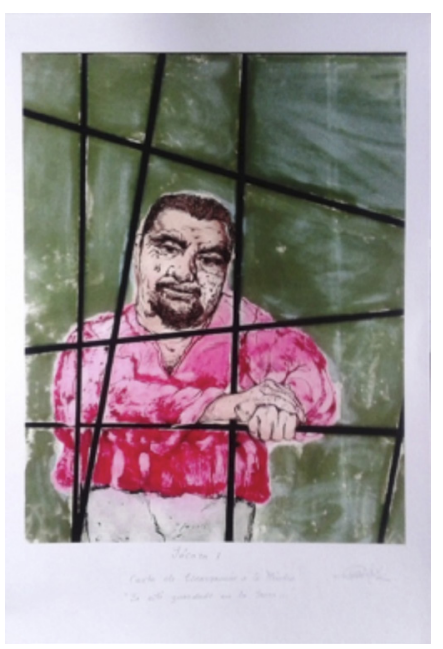

Figura 13

Amabel Míguez de la Sierra, Ya está metido en la trena tu querido Escarramán, 2011, técnica mixta.

(C) A. M. de la Sierra

Esta sensación de limite y separación, junto con el enfoque en fuera de campo, le añade a la imagen claves implícitas que permiten interpretar estas rayas negras como barrotes de una prisión y, por consiguiente, la palabra germanesca «trena» como sinónimo de «cárcel» o «prisión». La sensación de separación entre ficción y realidad, y pues, entre encarcelamiento y libertad, procede incluso de la mano izquierda de Escarramán sobre el barrote (Fig. 14) como para que la mirada se focalice en este elemento gráfico a partir del cual se establece el sentido de la ilustración. La mano es el punto de partida de la lectura de esta imagen, lo mismo que en el texto la mano ha sido la causa del encarcelamiento del jaque, una misma mano causa de matanzas y demás robos.

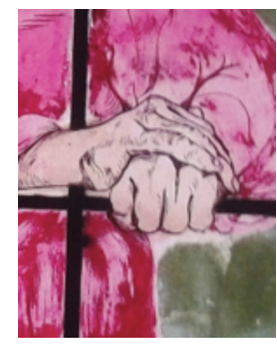

Figura 14

Amabel Míguez de la Sierra, Ya está metido en la trena tu querido Escarramán (detalle), 2011, técnica mixta.

(๑) A. M. de la Sierra 
Otro punto que merece la pena señalar es que no disponemos de ninguna descripción textual de Escarramán, excepto en el apéndice a las jácaras que constituyen los Bailes de Quevedo ${ }^{13}$, donde el autor le brinda al lector un complemento biográfico acerca de Escarramán, pero sin que estos datos poéticos intertextuales permitan realizar un retrato fiel de este prototipo rufianesco. Y sin embargo, Amabel Míguez de la Sierra nos ofrece un retrato gráfico del jaque, fruto de su propia imaginación; la imagen gráfica funciona aquí como prolongación de la imagen retórica, la artista se vuelve co-autora de la jácara quevediana, función exotópica de re-creación que Ricoeur ${ }^{4} 4$ llama «triple mímesis».

Este proceso va acompañado de una contemporaneización de las facciones de Escarramán en la jácara 1, cuyos rasgos recuerdan retratos de delincuentes contemporáneos como suelen ser los narcotraficantes por ejemplo, funcionando la ilustración según una lógica extra-semiótica implícita y con referencias socioculturales extra-enunciativas ubicadas en la mente del receptor.

«Respuesta de la Méndez a Escarramán», la ilustración a la jácara 2, sigue una lógica similar al texto. En efecto, las jácaras 1 y 2 son un díptico ético y estético, y sendas ilustraciones se articulan igualmente sobre un modo complementario. El vínculo entre ambas ilustraciones son los ya señalados barrotes de la «trena», representados aquí con líneas negras, que dos personajes de diminuto tamaño le están clavando en los riñones y el cráneo de quien se supone que será Escarramán (Fig. 15).

El desfase de proporciones entre la Méndez, sentada en un sofá con vestido que deja brotar el pecho izquierdo, y los dos personajes que están a nivel de su cabeza dan a entender que el receptor está asistiendo a los pensamientos de la iza, quien acaba de redactar la carta que percibimos en el respaldo del sillón (Fig. 16); además, está «Con un Menino del padre» en la parte izquierda de la obra, lo cual retoma el íncipit de la misma jácara. Esta segunda ilustración se ajusta pues al hipotexto escritural de Quevedo a la vez que autocita parte de la primera ilustración.

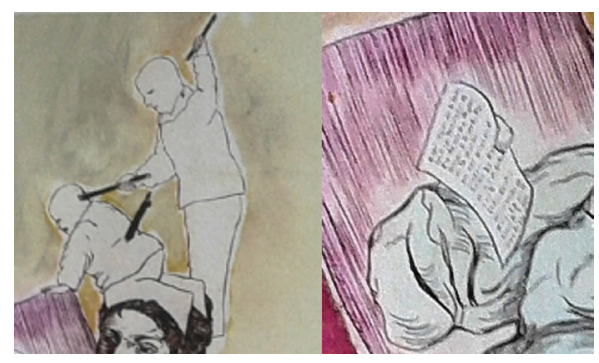

Figuras 15 y 16

Amabel Míguez de la Sierra, Respuesta de la Méndez a Escarramán (detalles), 2011, técnica mixta.

(C) A. M. de la Sierra

13. Ver el Baile «Los valientes y tomajonas» en particular.

14. Ricoeur, 1983 
Esta autocita iconográfica entre las ilustraciones 1 y 2 por parte de la artista, junto con señaladas hetero-citas iconográficas implícitas, son dignas de la estrategia poética del propio Quevedo ${ }^{15}$, y establecen un sistema inter-discursivo de referencias intra-enunciativas. A esto se le añade un contraste visual, dado que el hipotexto icónico postmoderno de la primera ilustración contrasta con los códigos visuales de la segunda que nos enfundan en un ámbito más barroco tanto por el tipo de vestido, el estilo de muebles como el juego del menino.

Ambas ilustraciones parecen también unir dos contextos enunciativos: el contemporáneo de la primera ilustración que remite al receptor postmoderno, y el barroco y germanesco de la segunda que se refiere a Escarramán. Este díptico gráfico establece pues una continuidad estética y temporal entre el texto del siglo XVII y los códigos del receptor postmoderno.

La lengua de germanía figura incluso en la cuarta ilustración, la ya comentada «Respuesta de Lampuga a la Perala» (Fig. 8). Vemos aquí en primer plano a un jaque con lo que podría ser un remo; lo tiene que imaginar el receptor-lector porque sale fuera de campo, lo mismo que la segunda sardina en segundo plano. La artista está ilustrando formas de germanía como por ejemplo «ser escribano naval» (v. 60), puesto que cuando rema en las galeras, el jaque traza círculos y rectas - «escribano»- en el mar -naval-. Aquí, el nexo entre ambos grabados del díptico es de tipo cromático: la paleta azul y los valores blanco, gris y negro.

\section{LA FIGURA DE LA IZA: ÉTICA Y ESTÉTICA}

En cuanto a técnica discursiva gráfica, llama la atención que las izas nunca, o casi nunca, desempeñan la función de admonitores; los jaques son los que le miran al receptor a los ojos desde la ficción. Se trata de las ilustraciones a las jácaras 1 , $3,4,6,11$ y 13, que nos presentan seis situaciones genéricas de la germanía y de las jácaras: Escarramán en la cárcel (Fig. 17), el mulato que le roba la iza La Perala al jaque Lampuga (Fig. 18), Lampuga galeote (Fig. 19), Montilla y sus «catorce navajas» (Fig. 20), Mojagán celebrando la hermosura de su iza (Fig. 21) y el jaque Gorgolla «descosido el cuerpo» (Fig. 22). Dicho de otra forma, estos seis admonitores encarnan otros tantos criterios que definen la categoría literaria de la jácara: prostitución y robos que llevan, sea a las galeras, sea a la cárcel, sea a la muerte y, de por medio, una relación epistolar que justifica el alejamiento y el recurso a la lengua de germanía. 

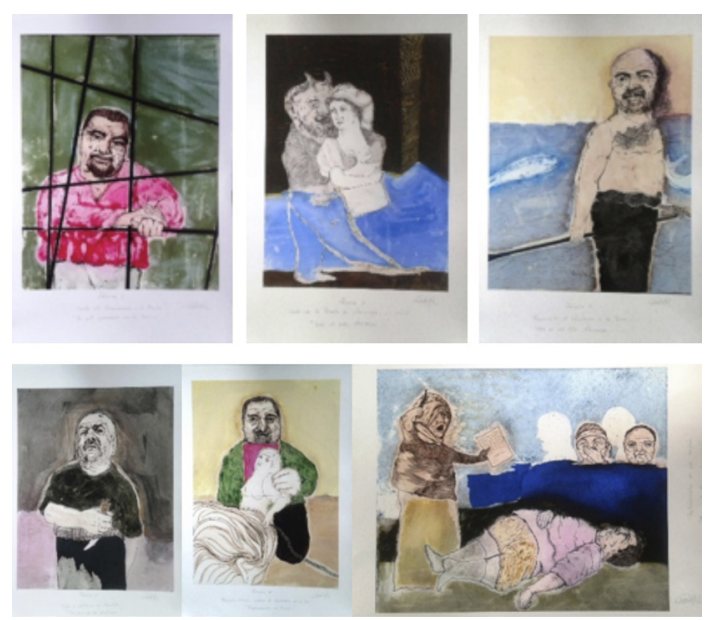

Figuras 17 a 22

Amabel Míguez de la Sierra, 2011, técnica mixta.

(c) A. M. de la Sierra

Solo dos izas, en las jácaras 10 y 15, desempeñan este papel de admonitores, la primera para dar testimonio de los malos tratos que padecen las izas por parte de todos - jaques, justicia, etc. - y la segunda para dar cuenta de su condición de prostituta. La ilustración a la jácara 15, «Jacarandina» (Fig. 23), responde a una cuestión que había planteado en un artículo del 2006 donde preguntaba cómo ilustrar la jácara «Jacarandina» sin dar en lo obsceno ${ }^{16}$. Amabel Míguez de la sierra da una estética respuesta, planteando cuerpos desproporcionados, deformados por el oficio de iza, cuerpos vueltos solo carne deshabitada, sin la menor dignidad y humanidad; en último plano, dos formas sin contenido, que simbolizan el jaque dueño de la iza, el padre de la germanía y los clientes que alquilan minutos de vida pertenecientes a estas izas. Las líneas gráficas se ablandan, esbozando cuerpos agotados y deshumanizados; los colores pálidos apenas hacen perceptibles lo que resultan ser cuerpos desvanecidos y desanimados, todo ello, en una especie de caída, como velas que se fueron derritiendo, ánimas que huyeron de cuerpos infernales. Lo único animado aquí parecen ser las cosas materiales - paredes, sábanas, etc.que llevan colores contrastados con rojos cálidos y azules fríos, lo cual infunde una forma de dinamismo, quizá el mismo que parece haber huido de los cuerpos. 


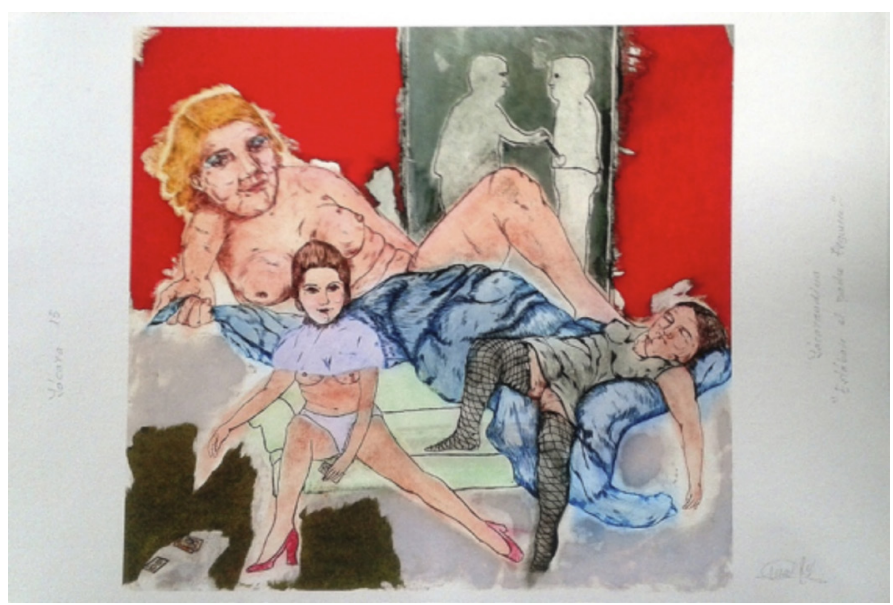

Figura 23

Amabel Míguez de la Sierra, Jacarandina, 2011, técnica mixta.

(c) A. M. de la Sierra

La artista representa aquí la característica básicamente física y material del mundo hampesco, totalmente yermo de preocupaciones espirituales y metafísicas, un mundo pues deshumanizado y sin rescate o salvación posible. Esta intención y técnica no resultan tan alejadas, aunque en distinta forma, de las preocupaciones de José Luis Cuevas en «Lo feo de este mundo» (Fig. 24), donde se plantean cuestiones filosóficas similares.

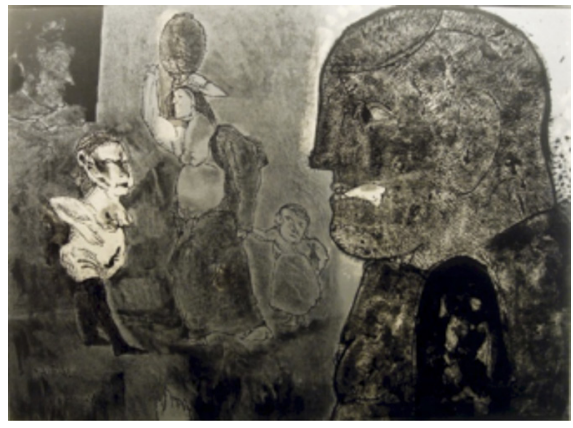

Figura 24

José Luis Cuevas, Lo feo de este mundo III, 1969, litografía, A/P, 56.5 × $76.3 \mathrm{~cm}$

(c) Museo José Luis Cuevas

\section{CONCLUSIONES}

La función gráfica de los personajes en las ilustraciones de Amabel Míguez de la Sierra ilustra pues no solo el contenido, sino incluso los criterios filológicos que definen el subgénero literario de las jácaras, en particular, las de Quevedo. 
El icono-texto de estas ilustraciones postmodernas desempeña una función meta-enunciativa que genera una reflexión acerca de la escritura de Quevedo, a la vez que crea nuevas formas de representación del prototipo rufianesco, formas arraigadas en los códigos estéticos del receptor de los siglos XX y XXI.

Amabel Míguez de la Sierra pertenece, pues, a una generación de ilustradores de textos clásicos de los que he señalado determinados rasgos comunes, a la vez que se distingue con una interpretación y técnica singulares. Prueba de ello es la ilustración a la jácara 12 (Fig. 25), donde no faltan manos, sino que sobran, en particular, en el jaque del segundo plano. Debido a una idéntica paleta cromática roja, las dos manos o puños pertenecen al mismo jaque, con lo cual, la artista no está representando el golpe, sino el movimiento de la mano.

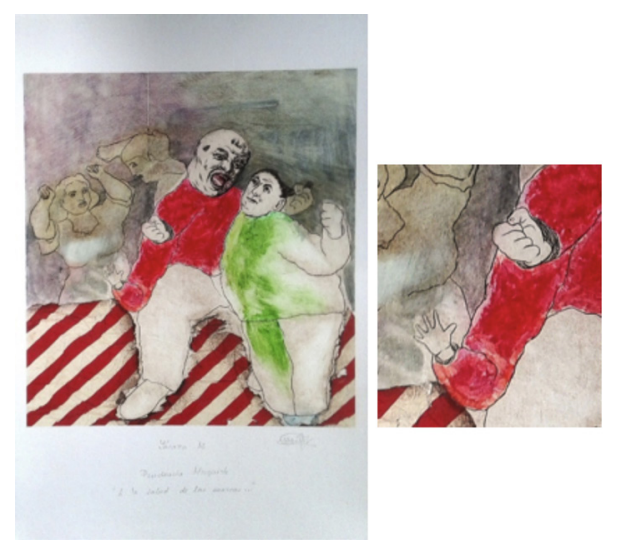

Figura 25

Amabel Míguez de la Sierra, Pendencia mosquito (y detalle), 2011, técnica mixta. (c) A. M. de la Sierra

Ilustración cinética, pues, totalmente única en el contexto bibliófilo, y que solo Antonio Zarco ${ }^{17}$, ilustrador de las Novelas ejemplares de Cervantes, intentó mediante un plano secuencia inspirado en el cine, en particular el cine neorrealista italiano de la década de los cuarenta ${ }^{18}$.

Mediante líneas que perfilan y deshumanizan, gracias a líneas que representan con el mayor realismo germanesco y recurriendo a superficies cromáticas de paleta cálida y fría, Amabel Míguez de la Sierra aparece como la única artista de los siglos XX y XXI que se habrá atrevido a representar a los rebeldes y marginales quevedescos del siglo XVII, tan modernos en su plasticidad textual y gráfica que se parecen a los de hoy. 


\section{BiBLIOGRAFÍA}

Ardenne, Paul, L'image du corps. Figures de l'humain dans l'art du XXe siècle, Paris, Editions du regard, 2001.

Berthelot, Jean-Michel, «Corps et société (problèmes méthodologiques posés par une approche sociologique du corps)», Cahiers internationaux de sociologie, LXXIV, 1983, pp. 119-131.

Brohm, Jean-Marie, Corps et politique, Paris, Jean-Pierre Delarge/Editions Universitaires, 1975.

Cuevas, José Luis, Homage to Quevedo, San Francisco, Graphic Gallery, 1969.

Deleuze, Gilles, Le Pli. Leibniz et le Baroque, Paris, Minuit, 1988.

Fernández Mosquera, Santiago, Quevedo: reescritura e intertextualidad, Madrid, Biblioteca Nueva, 2005.

Kerbrat-Orecchioni, Catherine, L'énonciation, Paris, A. Collin, 1980.

Levisi, Margherita, «Las figuras compuestas en Arcimboldo y Quevedo», Comparative Literature (Oregon), 20, 1968, pp. 217-235.

Maingueneau, Dominique, Les termes clés de l'analyse du discours, Paris, Seuil, 1996.

Maréchal, François, Testamento de don Quijote, Madrid, Casariego, 1987.

Marigno, Emmanuel, «Quevedo pornographe, ou comment illustrer la jácara "Jacarandina" sans tomber dans l'obscénité?», en L'obscène, dir. Jean-Claude Seguin, Lyon, Grimh-L.C.E.-Grimia, 2006, pp. 29-47.

Marigno, Emmanuel, Francisco de Quevedo. «Jácaras» (Edition critique), Lille, ANRT, 2000.

Marigno, Emmanuel, «Las Novelas ejemplares (1613) ilustradas por Antonio Zarco (1980): entre realismo y fantasía», en Cervantès et don Quichotte depuis le XXIe siècle / Cervantes y don Quijote desde el siglo XXI, ed. Emmanuel Marigno, Carlos Mata Induráin, Marie-Hélène Maux, Lyon, Orbis Tertius / Universitas, 2017, pp. 261-282.

Morreale, Margherita, «Quevedo y el Bosco, una apostilla a Los Sueños», Clavileño, 40, 1956, pp. 40-44.

Pozuelo Yvancos, José María, «Notas sobre la descriptio», Ínsula, 409, 1980, pp. 1-10.

Ricœur, Paul, Temps et récit I. L'intrigue et le récit historique, Paris, Seuil, 1983.

Saura, Antonio, Trois visions, Paris, Yves Rivière, 1971.

Zarco, Antonio, Rinconete y Cortadillo, Madrid, Casariego, 1980. 